\title{
HIGIENE E CONTROLO MÉDICO DA INFÂNCIA E DA ESCOLA
}

\author{
António Gomes Ferreira*
}

\begin{abstract}
RESUMO: Partindo da análise das dissertações apresentadas pelos alunos da Escola Médico-Cirúrgica do Porto, desde 1837 até ao início do século XX, verificamos que para além do somar de teses sobre assuntos relativos à criança, nos últimos 25 anos do Oitocentos, aumentou a variedade dos aspectos abordados. De facto, aos temas tradicionais, que rondavam os momentos da gravidez, do parto e do pós-parto, tratados de modo mais actualizado, juntavam-se outros que se debruçavam sobre determinadas doenças infantis ou sobre instituições dedicadas à infância. $\mathrm{Na}$ transição do século XIX para o XX, a escolarização começava também a ser alvo do discurso higienista. Contudo ele não se detinha somente nas condiçōes ambientais da escola, ele pretendia intervir no domínio pedagógico considerando que a pedagogia científica que se estava a construir não se podia consumar sem assentar na fundamentação do saber médico.
\end{abstract}

Palavras-chave: Criança. Educação. Escolarização. Higiene. Medicina.

\section{HYGIENE AND MEDICAL CONTROL OF INFANCY AND SCHOOL}

ABSTRACT: Analyzing the theses presented by the students of the Medical-Surgical School of Porto, between 1837 and the beginning of the $\mathrm{XX}^{\text {th }}$ century, we noted an increase not only of the number of theses on matters related to children, but also, in the last 25 years of the XIX ${ }^{\text {th }}$ century, of the diversity of themes studied. In fact, besides such traditional themes as pregnancy, delivery, and postpartum, treated in a more updated fashion, others emerged as

Doutor em Ciências da Educação pela Universidade de Coimbra e professor associado da Faculdade de Psicologia e de Ciências da Educação da mesma Universidade. Email: antonio@fpce.uc.pt 
those related to some children diseases or to the institutions dedicated to childhood. By the turn of the $\mathrm{XX}^{\text {th }}$ century, schooling also started to be addressed in the hygienist discourse. Yet, it was not restricted to the environmental conditions of the premises, but intended to interfere in the pedagogical field, considering that the scientific pedagogy that was being constructed could not be carried out but grounded on the medical knowledge.

Key words: Child. Education. Schooling. Hygiene. Medicine.

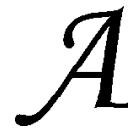

abordagem da higiene em Portugal tem uma longa tradição, merecendo mesmo a atenção dum rei da primeira metade do século XV, Dom Duarte, contudo não conseguiu fugir às preocupaçóes e às influências desses séculos mais recuados e permaneceu presa das considerações arábico-galénicas que caracterizavam a medicina de então. Ainda que nos séculos XVI e XVII encontremos algumas obras interessantes sobre este assunto, são em grande parte dedicadas à problemática das epidemias. Apenas duas parecem escapar a esta tendência, a de Fernando Rodrigo Cardoso (1602) e a de Fernão Solis da Fonseca (1626), que se debruçavam sobre as "seis coisas não naturais", tecendo considerações sobre o ar, a alimentação, o sono, a vigília, o exercício, no fundo sobre os aspectos que podiam condicionar a saúde dos indivíduos.

À medida que caminhamos do princípio para o fim do século XVIII vemos desenvolver-se uma modernização da abordagem da higiene. Para além dos livros sobre a peste, encontramos algumas obras na primeira metade do Setecentos, como a Ancora medicinal (Henriques, 1721) e a Arte com vida ou vida com arte (Leitão, 1738), que, embora continuem muito próximas do pensamento antigo, apresentam ideias novas muito aceitáveis. De facto, se ambas seguem muito de perto Galeno, a primeira, que parece ter tido muito sucesso dado que teve quatro edições em 25 anos, abordava a alimentação, o ar, a água, o sono, a vigília e demais aspectos tidos como condicionantes de uma boa saúde com base nos costumes dos seus conterrâneos. Contudo, a obra portuguesa de maior consideração neste domínio, publicada no século XVIII, é o Tratado da conservação da saúde dos povos (1756), de Ribeiro Sanches, que, começando por ocupar-se do ar, abordou um conjunto de aspectos de natureza sanitária, numa concepção tão ampla e tão precisa que tem sido considerado um verdadeiro tratado de medicina pública e preventiva. 
Curiosamente, não é nesse tipo de literatura que podemos encontrar especial atenção para com os cuidados a prestar à criança. Em geral, os aspectos relativos à higiene infantil aparecem abordados sobretudo em livros de pendor educativo ou inseridos em partes de obras médicas (Ferreira, 2000). Todavia, logo no início do século XVIII, Fonseca Henriques fazia publicar o seu Socorro Delphico (1711), monumental livro que muito se debruça sobre aspectos condicionantes do desenvolvimento e até da sobrevivência da criança. Sublinhe-se que as duas primeiras partes, das três em que se divide a obra, ocupam-se fundamentalmente da embriologia e da higiene da primeira infância.

Seria, contudo, já no aproximar do fim do século que se desenharia um maior interesse para com os cuidados higiénicos da criança. Nos finais da década de 1780, Henriques de Paiva fazia publicar o seu Aviso ao povo, que dedicava um espaço relativamente interessante aos cuidados a ter para com os mais pequenos, o mesmo acontecendo com uma tradução do francês, saída a público exactamente no mesmo ano da obra anterior (1787), e que significativamente se intitulava: Tratado da educação fisica, e moral dos meninos de ambos os sexos. Pouquíssimos anos depois, a Academia Real das Ciências reconhecia a importância e a necessidade de trabalhos sobre estes assuntos, publicando os livros de Francisco Melo Franco (1790) e de Francisco José de Almeida (1791) que tinham exactamente o mesmo título, Tratado da Educação Física dos meninos para uso da nação portuguesa, e abordavam sensivelmente os mesmos problemas de modo muito semelhante. Embora essas publicaçôes se propusessem a divulgar, resumida e simplificadamente, alguns dos conceitos e das práticas sobre a educação física dos meninos, elas apoiavam-se constantemente em importantes autores dos países europeus mais desenvolvidos, ${ }^{1}$ sem nunca distinguir as obras publicadas antes ou depois de Emile ou l'Education. ${ }^{2} \mathrm{Na}$ verdade, essas pequenas obras de puericultura apresentavam as posiçôes fundamentadas dos seus autores sobre aspectos tão diversos como o regime que convinha às mulheres grávidas e os cuidados a ter, por ocasião do parto, com a mãe e o recém-nascido, da necessidade dos banhos das crianças, do modo de as vestir, como amamentar e alimentar os meninos, da importância da prática do exercício físico e das precauçōes a ter com o sono. Ambos os autores acabaram por, mais uma vez, combater o opressivo conjunto de cintos, faixas e mantilhas que imobilizavam completamente o tronco e os membros da criança, propondo 
que se adoptassem roupas que não impedissem a liberdade de movimentos, e mostraram-se igualmente indignados com as mulheres que não amamentavam os seus filhos com o seu próprio leite. Embora não expusessem ideias muito originais, estes médicos pensavam na racionalidade das práticas usadas ou recomendadas com base numa modernizante postura crítica e indagadora. Esses autores eram grandes defensores duma medicina preventiva, sendo isso especialmente notório em Melo Franco, quer pelo seu empenhamento em favor da vacinação, quer pelo que escreveu em Elementos de higiene, um seu outro livro publicado já no século seguinte.

Durante boa parte do século XIX, a medicina portuguesa parece não ter dado continuidade ao esforço desenvolvido por alguns médicos, nas últimas décadas do Antigo Regime, sobre as condições particulares que condicionavam o desenvolvimento das crianças. No entanto, é bem provável que este refrear da atenção médica, em Portugal, deva-se aos problemas políticos surgidos após a revolução liberal (1820), nomeadamente à guerra civil que opôs absolutistas e liberais e que terminou em 1834. Porque "em guerra não se limpam armas", como diz o ditado popular, e a guerra fratricida e o combate ideológico exigiram um desgastante esforço de todos os que acreditavam que estavam em causa os valores fundamentais que deviam orientar a vida do país, torna-se compreensível uma menor atenção a problemas de fundo, crónicos, mas não dramáticos e decisivos quanto os que se prendiam com a sorte política do país que então se decidia. De qualquer modo, perante a escassez de publicaçóes de natureza médica sobre a infância é lícito concluir que Portugal, durante largas décadas do século XIX, não conheceu o interesse, verificado em países do centro da Europa, sobre o desenvolvimento físico das crianças. Parece-nos, no entanto, que, na passagem do terceiro para o quarto quartel do Oitocentos, inicia-se uma fase de maior investimento médico na infância, primeiramente com a publicação do $\mathrm{Ma}$ nual da higiene da infância, ou conselhos às mães de familia sobre o modo de criar e educar os filhos (Abranches, 1866), e posteriormente com as obras do professor da Faculdade de Medicina da Universidade de Coimbra, Augusto Filipe Simões, publicadas nos anos de 1870.

Considerando as mais de 900 dissertações apresentadas pelos alunos da Escola Médico-Cirúrgica do Porto, desde 1837 até ao início do século XX, verificamos que a infância não se constituía como especial preocupação dos futuros médicos. Desse numeroso grupo de textos, apenas meia centena abordava de algum modo a proble- 
mática da sobrevivência ou a saúde infantil. No entanto, neste número consideramos títulos tão heterogéneos como Breves consideraçôes sobre a higiene da gravidez, Puericultura intra-uterina, Algumas palavras sobre as causas do aborto, $O$ parto prematuro artificial, $A$ assistência à mulher grávida e ao recém-nascido, O regime lácteo, Evolução precoce (Breve estudo), Breve estudo sobre as oftalmias purulentas dos recém-nascidos etc.

Uma análise mais detalhada aos temas dessas dissertaçôes mostra que, ao longo de mais de meio século, as preocupações para com os problemas específicos das crianças foram se alargando. De facto, poucas são as teses que se debruçavam decididamente sobre a criança até ao fim do terceiro quartel do século XIX. A maior parte das que têm alguma relação com esta temática tratava dos aspectos relacionados com as técnicas do parto de que são exemplos, entre outros, Em todos os partos naturais e espontâneos o mecanismo é sempre o mesmo (1865), Encravação da cabeça do feto e suas conseqüências (1866), Algumas considerações sobre as indicaçôes da operação cesareana (1865). As pouquíssimas excepções dizem respeito a aspectos inerentes à gestação, ao parto e aos cuidados com os recém-nascidos como são os casos de $A$ saúde da infância ou conselhos às mães sobre a conservação dos filhos durante os últimos tempos da prenhez e sua educação física no primeiro periodo da vida comum (1865), Consideraçôes práticas sobre alguns dos obstáculos e acidentes que o parteiro deve evitar para salvar a vida da mãe e do filho (1864), Algumas consideraçóes sobre a escolha das amas de leite (1864).

Com o avançar do último quartel do século, as dissertações que se interessavam pela criança cresceram em número e contemplaram novos temas. Ainda nos anos de 1870, aparecem textos cujos títulos mostram essa diversificação dos assuntos: Breves consideraçōes acerca da educação física e moral das crianças durante a primeira infância, em 1877; Creches, em 1878; Higiene das escolas, em 1879; e, no ano seguinte, $A$ higiene e o trabalho das crianças e Breves consideraçôes sobre a alimentação da primeira infância. Nesse momento, para além dos aspectos mais relacionados com os primeiros tempos de vida, são abordados vários outros que se prendem com uma infância mais tardia e seguem uma orientação de higiene social.

As duas últimas décadas do Oitocentos assistem ao desenvolvimento dessa mesma tendência. A higiene perspectivada pelo ângulo da responsabilização individual continuava a ser motivo de dissertações como Algumas consideraçōes sobre higiene da primeira infância 
(1889), Algumas regras de higiene ocular da infância (1889), Higiene da primeira infância (1891), A higiene e a educação psiquicas nos três primeiros anos de vida (1898). Em geral, as abordagens dessa tendência incidiam sobre as crianças mais pequenas, e, por isso, as indicações dadas dirigiam-se para os primeiros anos de vida. Bastante recorrente nesse grupo de dissertações é o assunto da alimentação das crianças, surgindo, nomeadamente, vários trabalhos que se debruçam especificamente sobre este candente problema da criação dos mais pequenos, como Algumas considerações sobre a alimentação da primeira infância (1890), Algumas consideraçôes sobre a amamentação (1892), Duas palavras sobre o leite e o regime lácteo (1896), Puericultura (contribuição ao estudo do aleitamento) (1898).

A higiene merece, todavia, abordagens que apelam para intervenções de apoio público. A ideia de que não se podia continuar a responsabilizar unicamente a família pelas condições de desenvolvimento da criança dá origem a novas perspectivas de actuação. Começa a existir, cada vez mais, uma consciência de que é preciso actuar sobre a família e também além dela. Em dissertações como Hospitais de crianças (1890) e $A$ mortalidade das crianças e a assistência pública (1894) isso é por demais evidente, mas outros trabalhos denunciam também a necessidade de se encarar a protecção da criança dum ponto de vista da higiene social, como A higiene e o trabalho das crianças (1880), ou a ligação do estado sanitário da população com as condições da educação, como Questôes de patologia e higiene social (1891) e Algumas palavras sobre as relaçôes da educação física e moral com a patologia e a sociedade (1883).

Nos anos próximos da passagem para o século XX, não se registam grandes alterações. Os títulos são, praticamente, os mesmos e os fundamentos retóricos também. No entanto, é possível que os médicos, na transição do século, se sentissem bem mais confiantes na sua capacidade de intervir sobre a criança. Em boa parte isso resultava de se verem como o único corpo profissional com formação para uma intervenção científica sobre a infância.

Olhando para as dissertações apresentadas nos últimos anos do século XIX e no princípio do século XX, parece perceber-se uma maior vontade dos médicos em encarar a especificidade das doenças que mais atacavam as crianças. Títulos como Breves consideraçôes sobre gastro-enterite infantil aguda (1893), Diarreias infantis (tentativa de sòroterapia) (1897), A meningite tuberculosa na cri- 
ança (1898), Dipheteria no Porto. Notas clínicas, bacteriológicas e demográficas (1904), Etiologia e patogenia da escarlatina no Porto (1905), entre outros, traduzem, pelo menos, maior atenção aos problemas de saúde que maior mortalidade causavam em Portugal - gastro-enterite, bronquite, pneumonia, tuberculose e varíola ( $\mathrm{Ri}$ beiro, 1902).

A dominância dos pressupostos positivistas e o acentuado desenvolvimento das ciências biomédicas conferiram à medicina uma auto-confiança que a abalançou a abrir várias frentes de intervenção, algumas das quais vieram, posteriormente, a converter-se em especialidades médicas. Para além da intervenção sobre o corpo, a medicina perspectivava alcançar o indivíduo como um ser social. Por outro lado, o cientificismo, cada vez mais dominante entre a intelectualidade, era receptivo aos fundamentos que suportavam a compreensão médica sobre as condicionantes mesológicas na condição sanitária do indivíduo. No final do século XIX e no princípio do seguinte, o campo médico parecia querer abarcar tudo o que dissesse respeito à qualidade de vida de cada pessoa. Por ele perpassavam interpelações discursivas biológicas, psicológicas e sociológicas tendentes a formalizar a compreensão totalizadora sobre o indivíduo e, principalmente, sobre a natureza e as condições do seu desenvolvimento. A intervenção do saber médico sobre aspectos inerentes ao fenómeno da escolarização de então decorre desta colocação algo tendencialmente hegemónica em que se posicionava a medicina da época.

Remetendo-nos às dissertações produzidas no âmbito da Escola Médico-Cirúrgica do Porto, já vimos que no final da década de 1870, uma dissertação interessou-se pela higiene escolar. Embora estejamos perante uma tímida ingerência médica na escola, ela significa que já existia uma intenção de medicalização da escola, num tempo em que esta parecia vir a enquadrar parte substancial da população infantil. O próprio autor da dissertação, Emygdio Pereira da Cruz, demonstra ter bem consciência disso. Escreve ele: "O estudo da hygiene das escolas, como entidade de vida independente, é de recente data. A sua historia acha-se mais ou menos confundida com a da instrução popular, de tal modo que se torna impossível fallar d'uma sem alludir mais ou menos á outra” (1879, p. 3).

Este futuro médico tem clara consciência de que está perante um fenómeno que despontava, a escolarização, e que havia conveniência de esta ser considerada do ponto de vista médico. 
Escrevendo para futuros pares assume de modo peremptório a legitimidade científica de tal intervenção:

Cada meio tem uma hygiene sua, que lhe é própria, e o da escóla também a deveria ter. E tem-na. É por isso que na sciencia se encontram regras relativas á situação, exposição, luz e mobília d'estas casas d'instrucção, aos trabalhos, attitudes, exercícios, jogos e doenças dos seus habitantes temporários - os alumnos. E hoje que as escolas se multiplicam, que por toda a parte se proclama a instrucção obrigatória, compellindo todos os indivíduos á frequencia escolar, mais que nunca abundam argumentos para se justificar a legitima intervenção da hygiene n'este grupo de edifícios de que estamos fallando. (Idem, p. 2)

Podíamos ficar na dúvida, com base nestas afirmações, se a reivindicação duma higiene escolar se fazia à luz de uma ciência desinteressada e no exclusivo interesse da população que passava pelas escolas. $\mathrm{Na}$ verdade, a necessidade de atender a condições apropriadas ao desenvolvimento das crianças tinha igualmente em vista justificar a intervenção dum profissional específico: o médico. Para este se criava mais um campo de actuação. As propostas do autor da dissertação Higiene das escolas não deixam margem para dúvidas:

Cada escola deveria ser regularmente visitada por um medico, que examinasse o estado de saude dos alumnos e as suas condiçóes de salubridade do edifício. D'isto faria um relatorio, que enviaria á repartição competente.

Este serviço deveria ser retribuído, pois que quando o não fosse, necessariamente deixaria de ser feito com a regularidade requerida. (Idem, p. 121)

Para além da reivindicação de carácter corporativo que se evidencia das propostas de Pereira da Cruz, desenha-se já no seu pensamento, ainda que de forma pouco explícita, também a pretensão do controlo do espaço pedagógico. No seu entender, o médico, para além de dar conta das condições físicas da escola e das doenças das crianças que a frequentavam, deveria prestar igual atenção "aos alumnos, inquirindo do trabalho e do repouso que teem, dos exercícios physicos que executam, expondo os factos principaes que pediam urgente substituição" (idem, p. 122). Estas palavras se mostram consistentes com a estruturação da dissertação apresentada por este futuro médico, pois que inclui capítulos sobre "O edifício escolar", "A aula", "A mobília da escóla”, e também sobre as "Doenças escolares e vigilancia medica das escólas" e a "Higiene do aluno", onde não se inibe de avançar com posições de natureza 
pedagógica, nomeadamente, dando indicaçóes sobre como proceder com o trabalho intelectual:

Para que a intelligencia da creança se não cance, é necessario que o trabalho esteja regulado de modo que alternem constantemente os exercicios intelectuaes e os exercicios physicos.

Assim, após uma hora de constante trabalho de intelligencia, deve fazerse seguir um intervallo de descanço ou uma outra hora em que a creança se entregue a outros exercicios, como o desenho, a gymnastica e a musica.

Se operarmos uma divisão do trabalho, obdecendo a estes princípios, poderemos ficar certos de que nem o corpo nem a intelligencia do alumno se cançarão.

Emquanto ao modo de o alumno aprender, seria de extrema vantagem que o professor desse ás suas lições um caracter tam pratico quanto possível.

Effectivamente, tudo quanto é theoria coaduna-se pouco com a intelligencia d'uma creança; e se quizermos que ella adquira conhecimentos theoricos é necessário redusir-lh'os a exemplos, explicar-lh'os practicamente e não obrigar essa creança a decorar authómaticamente as palavras sem comprehender as ideias que estas representam.

Deveria também o professor estudar o grau de capacidade de cada alumno para não cahir na inconveniência de ir pedir a uma intelligencia mais do que élla póde dar. (Idem, p. 109-110)

Apesar de o assunto da educação intelectual não merecer muitas mais linhas do que as da transcrição, esta não deixa de ser bem elucidativa acerca do alcance da medicalização da escola. Se a autoconfiança médica manifestava declarada pretensão de se intrometer na discussão pedagógica de âmbito escolar, isso não devia provocar grande estranheza, já que há muito que a higiene permitia aos médicos intervir sobre a educação da infância. Por outro lado, a grande maioria dos aspectos que a higiene escolar se propunha abarcar relacionava-se com as condições sanitárias propiciadas pelas escolas e isso era assunto para médicos. Todavia, a rápida abordagem ao modo como se devia realizar o trabalho intelectual na escola parece querer demonstrar a vontade, não explicitamente enunciada, de que tal assunto viesse a alargar o âmbito da higiene escolar. Nas décadas seguintes isso se verá confirmado. No que diz respeito às dissertaçóes da Escola Médico-Cirúrgica do Porto, encontramos em títulos como Algumas palavras sobre os efeitos, tratamento e meio de prevenir o esfalfamento mental (1898), Breves consideraçôes sobre a sedentariedade escolar e esfalfamento cerebral (1902), Duas palavras sobre higiene es- 
colar (1903) e Fadiga intelectual em pedagogia (1903), testemunhos claros de que o trabalho intelectual realizado em contexto escolar passara a constituir objecto de abordagem médica.

Como é natural, os trabalhos mencionados diferem uns dos outros. No entanto, as diferenças entre os que se debruçam sobre o "esfalfamento mental" derivam, sobretudo, de se constituírem como textos produzidos por dois autores e em que um destes não quer ser acusado de plagiar o outro. De qualquer modo, em ambos os casos, o assunto abordado tende a encerrar-se num discurso médico, que, por vezes, quase se esquece das preocupações pedagógicas que motivam a dissertação. Mesmo assim, deve salientar-se que o trabalho apresentado por António José Pimenta Freire, em 1902, intitulava-se precisamente Breves consideraçôes sobre a sedentariedade escolar e esfalfamento cerebral. $\mathrm{Na}$ verdade esta dissertação apresenta um esforço muito mais conseguido da abordagem médica sobre a actividade escolar do que Algumas palavras sobre os efeitos, tratamento e meio de prevenir o esfalfamento mental, ainda que permanecesse num registo preponderantemente fisiológico e clínico.

Especialmente interessante para verificarmos como Pimenta Freire tenta passar da demonstração do "esfalfamento physico" para o "esfalfamento cerebral” é o terceiro capítulo da referida tese. Ele próprio diz:

É para mostrar que um e outro dependem das mesmas causas, são analogos na sua pathogenia, que accrescentamos ao nosso obscuro trabalho mais este capitulo, em que estudaremos e mostraremos as analogias que existem entre o trabalho physico e o trabalho intellectual, analogias que naturalmente se estenderão aos seus effeitos e, portanto, ao seu esfalfamento que um e outro determinam, quando em excesso.

Tanto o trabalho do corpo como o trabalho do espírito não são mais do que manifestações differentes da energia vital. Se bem que diversos na sua fórma, estão, no entanto, submettidos ás mesmas leis physiologicas, poisque as condições de trabalho são as mesmas para o cérebro que pensa, para o músculo que se contrahe, para a glândula que segrega. (1902, p. 57-58)

Nas páginas imediatamente seguintes, tal como anunciara, o autor procura socorrer-se das experiências de fisiologistas para demonstrar que o cérebro, como o músculo, "é sede de uma congestão activa todas as vezes que trabalha" (p. 59) e que "tanto no cérebro que pensa, como no músculo que se contrahe, em virtude da maior actividade das combustões, há uma destruição mais activa de certos 
tecidos - os de reserva - destinados a alimentar essas combustões" (p. 61). Desse modo, em consequência do trabalho cerebral excessivo, a maior actividade das combustôes dava origem à "accumulação de productos de desassimilação no organismo", todas as vezes que esse trabalho não fosse entrecortado por períodos de repouso suficientemente longos. Dessa acumulação resultava o "esfalfamento cerebral” (p. 61).

Ora, em sua opinião, tal como acontecia com o esfalfamento físico, também o cerebral tinha efeitos nefastos para o desenrolar das doenças. De acordo com o que recolhera de autores estrangeiros, era nos denominados "esfalfados" que se encontrava grande número de afecções cerebrais - "congestão, hydrocephalia aguda, meningite, periencephalite diffusa, amollecimento cerebral, loucura ou simplesmente o exgottamento nervoso" - diferentes nevroses - "epilepsia, chorêa" -, entre outros problemas como "as enxaquecas rebeldes, a insomnia, os pezadêlos, a agitação e as allucinações dos sentidos, principalmente da vista” (p. 65). Compilação idêntica de doenças favorecidas pelo cansaço cerebral podemos encontrar numa outra dissertação apresentada no ano seguinte (1903) por Ludgero Soares Moreira. Escreve este a determinada altura:

Em um grau mais avançado, apparecem as doenças nervosas, como consequencia do excesso de trabalho intellectual.

C. Browne verifica o enfraquecimento crescente da raça, o accrescimo do nervosismo e colloca em primeiro logar, entre as causas, o systema de educação que tende a exagerar a actividade e susceptibilidade dos nervos.

A hysteria, epilepsia, neurasthenia, a alienação mental contam-se com frequencia na população escolar. (1903, p. 109-110)

Como vemos, as doenças atribuídas às condiçōes a que se submetiam os alunos nas escolas eram muitas e variadas. $\mathrm{O}$ ambiente escolar ainda era tido por facilitar o desenvolvimento da tuberculose e da miopia. Ambos os autores que vimos seguindo apresentam estatísticas para serem mais persuasivas as suas asserções. Soares Moreira, seguindo dados de 1884, salienta que, na Itália, "em 552 óbitos de estudantes de mais de 15 annos, $48,7 \%$ dos rapazes e $61,5 \%$ das raparigas eram causados pela tuberculose" (1903, p. 110); Pimenta Freire serve-se das estatísticas de Wirchow para mostrar que, entre os estudantes, a tuberculose atinge 4,81\%, dos 5 aos 10 anos, 12,96\%, dos 10 aos 25 anos, e 31,88\%, dos 15 aos 20 anos (1902, p. 41). Relativamente à miopia, é curioso que ambos se refiram aos resulta- 
dos dum trabalho de Cohn, ainda que os dados apresentados por Soares Moreira (1903, p. 88) se mostrem com maior precisão: a miopia atingia $1,4 \%$ das crianças, nas escolas rurais, e 6,7\% das escolas elementares, $26 \%$ dos alunos dos liceus e $59 \%$ dos universitários. No seguimento da apresentação dos dados, Pimenta Freire não perde a oportunidade para sublinhar a sua posição sobre as funestas consequências do cansaço cerebral, acrescentando:

Ainda mais. A maior parte dos ophtalmologistas concordam que essa doença se produz desde o segundo anno da escóla, e se vae aggravando á medida que o tempo e gráo escolares vão augmentando.

A razão d'este aggravamento durante os ultimos annos do estudo, parece-n'os poder explicar-se pela maior frequencia do esfalfamento cerebral n'esse período. (1902, p. 63)

A leitura destes trabalhos quase nos remete para a perversidade da escolarização. Afinal, a escola, que devia formar cidadãos úteis a uma sociedade progressiva, acabava por formar pedantes enfezados. Pior, aqueles que nela permaneciam mais tempo tendiam a sofrer mais as doenças. E a escola não só roubava a saúde física como também a psicológica. Não deixa de ser significativo que, num tempo em que se dava uma crescente valorização social da escolaridade, o discurso médico viesse acentuar o carácter doentio da escola. Contudo, é perceptível que não existe nenhuma má vontade da medicina à escolarização. Pelo contrário, a ideia mais explícita é obstar que a ênfase na generalização da escolaridade se faça a qualquer preço, denunciando as condições a que estavam sujeitos os alunos. Assim sendo, o corpo médico assumia uma posição política, pois a radicalidade da sua leitura da situação escolar devia impelir as autoridades públicas a modificarem o que prejudicava a saúde dos alunos. No entanto, a amplitude da radicalidade da denúncia, ao abranger tanto as condiçôes físicas como o processo de ensino, procurava também legitimar a intervenção médica no campo pedagógico, que devia incidir tanto sobre os casos particulares e, portanto, contemplar uma dimensão "clínica", como sobre as orientaçôes e os processos que o ensino devia seguir. Santos Silva, na sua dissertação Fadiga intelectual em pedagogia (1903), não podia ser mais explícito quanto a esta pretensão, condensando-a numa citação retirada de Albert Mathieu:

É aos médicos que pertence o mais bello papel na evolução que sonhamos. É a elles que pertence, sobretudo, convencer as famílias, o corpo d'ensino, os poderes publicos, da necessidade d'uma reforma radical, não 
sómente nos programmas mas, principalmente, nos methodos d'ensino e nos costumes escolares. Tem a autoridade desejada para falar alto e firmemente em nome da hygiene e tem o indeclinável dever de o fazer. (P. 30)

Longe vai o tempo em que a higiene, baseando-se em Galeno, debruçava-se sobre pouco mais que as epidemias ou sobre aspectos como o ar, a água, a alimentação, o sono, a vigília e o exercício. Largas décadas separam estes tempos daqueles em que a higiene se começava a preocupar com os cuidados do corpo das crianças mais pequenas. No início do século XX, a medicina encontra-se auto-confiante e entende que deve protagonizar a reforma da sociedade. Só ela se acha em condiçôes de compreender cientificamente o indivíduo e de agir em conformidade sobre ele. Mas, se outrora apostou sobretudo em agir sobre o corpo, agora pretende também se debruçar sobre aspectos psicológicos e educativos. Se desde os finais do Setecentos vinha produzindo um discurso dirigido particularmente às famílias e aos pais, a partir dos últimos anos do século XIX começa a querer intervir no domínio escolar. A partir dessa altura, o discurso médico quer a pedagogia sob o controle da sua fundamentação. A pedagogia científica que se estava a construir não podia realizar-se sem o contributo médico.

\section{Notas}

1. A educação da criança foi motivo para o aparecimento de uma abundante e multifacetada literatura especializada (Moral, 1976).

2. Rousseau limitou-se praticamente a repetir o que os médicos do seu tempo já tinham dito (Mercier, 1961).

Referências bibliográficas

AGUIAR, J.M. Puericultura intra-uterina (estudo de estatistica). Porto: Typ. Occidental, 1899.

ARIÈS, P. L'enfant et la vie familiale sous l'Ancien Régime. Paris: Seuil, 1973.

BADINTER, E. L'amour en plus : histoire de l'amour maternel (XVIIeXXe siècle). Paris: Flammarion, 1980.

BORGES, Z.M.S. Algumas regras de higiene ocular da infância. Porto: Typ. Elzeviriana, 1889.

CARDOSO, B.C. Consequências da alimentação prematura. Porto: Typ. Gutenberg, 1895. 
CARVALHO, F.S. A mortalidade das creanças e a assistencia publica. Porto: Typ. Cristovão A. Rodrigues, 1894.

CASTRO, L.A.R.V. A meningite tuberculosa na criança. Porto: Typ. José Frutuoso da Fonseca, 1898.

CASTRO, L.B.F. Breves consideraçôes sobre a alimentação da primeira infância. Porto: Typ. Viúva Gandra, 1880.

CHAVES, A. Creanças, educação e hygiene. Porto: Typ. A. F. Vasconcellos, 1902. CRUZ, E.P. Hygiene das escolas. Porto: Typ. Occidental, 1879.

CURADO, J.R.G. O regime lácteo: suas principaes indicações. Porto: Typ. Academica, 1892.

D'EÇA, P. d'A. Hospitais de crianças. Porto: Typ. Occidental, 1890.

FELGUEIRAS, N.M. Apontamentos sobre educação physica. Porto: Typ. Occidental, 1882.

FERREIRA, A.G. A criança em dois tratados setecentistas de puericultura. Revista Portuguesa de Pedagogia, Coimbra, v. 21, 1987.

FERREIRA, A.G. A criança no conhecimento médico de seiscentos. Revista Portuguesa de Pedagogia, Coimbra, v. 23, 1989.

FERREIRA, A.G. Gerar, criar, educar: a criança no Portugal do Antigo Regime. Coimbra: Quarteto, 2000.

VIEIRA FILHO, J.J. Puericultura: contribuição ao estudo do aleitamento. Porto: Typ. José da Silva Mendonça, 1898.

FREIRE, A.J.P. Breves consideraçōes sobre a sedentariedade escolar e esfalfamento cerebral. Porto: Typ. Azevedo, 1902.

GÉLIS, J. L'arbre et le fruit, la naissance dans l'Occident moderne: XVIeXIXe siècle. Paris: Fayard, 1984.

GÉLIS, J.; LAGET, M.; MOREL, M.-F. Entrer dans la vie: naissances et enfances dans la France tradicionnelle. Paris : Gallimard, 1978.

SOARES JUNIOR, A.C. Dipheteria no Porto: notas clínicas, bacteriologicas e demographicas. Porto: Typ. Azevedo, 1904.

LAGET, M. Naissances : l'accouchement avant l'age de la clinique. Paris: Seuil, 1982. 
LIMA, A.M.S. A hygiene e o trabalho das creanças. Porto: Imprensa Commercial, 1880.

LIMA, M.C. d'Araujo. Creches. Porto: Typ. Oriental, 1878.

LOBO, A.D. A saude da infancia ou conselhos ás mães sobre a conservação dos filhos durante os ultimos tempos da prenhez e sua educação physica no primeiro periodo da vida commum. Porto: Typ. José Pereira da Silva, 1865 .

MAIA, E. O parto prematuro artificial. Porto: Imprensa Commercial, 1894.

MARTINS, A. A higiene e a educação psíquicas nos três primeiros anos de vida. Porto: Typ. Academica, 1898.

MERCIER, R. L'enfant dans la société du XVIIIe siècle avant l'Émille. Dakar: Université de Dakar, 1961.

MONTEIRO, I.F. Diarreias infantis (tentativa de sòroterapia). Porto: Typ. Occidental, 1897.

MOREIRA, L.A.S. Duas palavras sobre higiene escolar. Porto: Typ. Occidental, 1903.

MORAL, M.F. Théories et pratiques de l'allaitement en France au XVIIIe siècle. Annales de Démographie Historique, Paris, 1976.

MOURA, F.A.M. Algumas consideraçôes sobre a escolha das amas de leite. Porto: Typ. Manoel José Pereira, 1864.

PARRA, F.I. Algumas palavras sobre os efeitos, tratamento e meio de prevenir $o$ esfalfamento mental. Porto: Typ. Morgado, 1898.

PEIXOTO, D.D. A amamentação. Porto: Typ. Azevedo, 1898.

PIMENTEL, A.V.G. Algumas considerações sobre a amamentação. Porto: Imprensa Moderna, 1892.

PROENÇA, A.A. Algumas palavras sobre a hygiene da primeira infancia. Porto: Typ. A. F. Vasconcellos, 1901.

RIBEIRO, G.U.C. A mortalidade infantil no Porto. Porto: Typ. da Real Officina de S. José, 1902.

SANTOS, S.M. Duas palavras sobre o leite e o regimen lácteo. Porto: Typ. da Real Officina de S. José, 1896. 
SARMENTO, A.M. Hygiene da primeira infância. Porto: Imprensa Portugueza, 1891.

SHAHAR, S. Childhood in the middle ages. London: Routledge, 1990.

SILVA, J.A.F. Breves consideraçôes sobre gastro-enterite infantil aguda. Porto: Typ. Gandra, 1893.

SILVA, S. Fadiga intelectual em pedagogia. Porto, 1903.

SOUTO, R.M.N. Questôes de patologia e higiene social. Porto: Typ. Occidental, 1891.

TRIGO, J.M.N. Algumas considerações sobre a alimentação da primeira infância. Porto: Typ. da Empreza Litteraria e Typographica, 1890.

TUCKER, M.J. The child as beginning and end: fifteenth and sixteenth century English childhood. In: Demause, L. (Ed.). The history of childhood: the untold story of child abuse. New York: Peter Bedrick, 1988.

VALLE, A.M.C. A alimentação artificial dos recem-nascidos: breves considerações. Porto, 1880.

VAZ, F.F.C. Algumas palavras sobre as relações da educação física e moral com a patologia e a sociedade. Porto: Typ. A. J. da Silva Teixeira, 1883. 